\title{
A emergência de novas latitudes no mundo das artes: o projeto Latitude e a inserção da arte brasileira no mercado global
}

Resumo

A partir da constatação da crescente participação da arte contemporânea brasileira no mercado internacional, este artigo se propõe a compreender a atuação do projeto Latitude como uma das principais ferramentas de internacionalização dessa produção. Atuando sob a configuração de parceria público-privada, o Latitude se apresenta como uma plataforma de negócios (para as galerias) e de visibilidade (para os artistas) que inclui desde o auxílio em questões burocráticas de exportação até a organização de visitas de diretores de instituições e de colecionadores internacionais a museus, instituições, feiras e galerias nacionais. No entanto, esse tipo de parceria nos leva a questionar as atuais políticas públicas para o desenvolvimento do setor, sua esfera de atuação, resultados e reais beneficiários.

Palavras-chave: Mercado de arte, internacionalização, projeto Latitude 


\section{The emergence of new latitudes in the art world: the Latitude project and the insertion of Brazilian art in a global market}

\section{BRUNA WULFF FETTER}

\section{Abstract}

Based on the increasing participation of Brazilian contemporary art in the international market, this article aims to understand the role of the Latitude project as a major tool of internationalization of this production. Acting under the setting of public-private partnership, the Latitude project presents itself as a business platform (for galleries) and also as a visibility one (for artists) that range from assistance in exportation bureaucratic issues to organizing visits of institution directors and international collectors to Brazilian museums, institutions, fairs and galleries.

Keywords: Art market, internationalization, Latitude project However, this type of partnership leads us to question the current public policies for the development of the sector, its sphere of action, results and actual beneficiaries. 


\section{Relevância no contexto global: deixamos a categoria "Outros"}

Em um contexto no qual a arte brasileira - em especial a arte contemporânea brasileira - encontra-se em evidência no cenário internacional, cabe aqui questionar a atuação do governo federal no processo de internacionalização na arte nacional, através de suas intenções e estratégias declaradas publicamente, assim como dos resultados obtidos até o momento.

Tal evidência da ascensão da arte brasileira a uma posição de maior prestígio no cenário internacional pode ser constatada através de diferentes indicadores. No entanto, talvez o mais emblemático neste sentido seja a inclusão do Brasil, pela primeira vez na história, no TEFAF Art Market Report de 2013. Preparado pela economista irlandesa Clare McAndrew, este relatório a respeito da evolução e das tendências do mercado da arte é publicado anualmente por ocasião da maior feira de arte e antiguidades do mundo, a TEFAF Maastricht. Localizada na cidade de mesmo nome na Holanda, a TEFAF Maastricht historicamente tem se preocupado em registrar e pesquisar as mudanças ocorridas no mercado de uma forma detalhada. O título do relatório deste ano é "The Global Art Market, with a focus on China and Brasil"'.

A partir desse relatório, passamos a ter uma mensuração do tamanho do mercado brasileiro e sua representatividade em termos de vendas em relação ao mercado global. Com aproximadamente $€ 455$ milhões em vendas no ano de 2012, o mercado brasileiro corresponderia a $1 \%$ do volume de vendas global, figurando pela primeira vez como um player $^{2}$ a ser observado no mercado (e não mais na categoria genérica "Outros", ou seja, daqueles países cujo volume de transações não é significativo dentro do contexto global). 
Ainda segundo esse relatório, o Brasil teria um superávit comercial de arte desde 2009. As exportações chegaram a $€ 41$ milhões em 2011, com um avanço de mais de $1.500 \%$ ao longo da última década. As importações são consideravelmente mais baixas, tendo atingido $€ 12$ milhões nesse mesmo ano. No entanto, o ponto de destaque sugerido por este estudo a respeito do mercado de arte brasileiro não está nos artistas, nem nas obras, instituições ou galerias.

A pesquisa coordenada por McAndrew aponta a emergência de uma rede de colecionadores com alto poder aquisitivo, que está crescendo rapidamente em quantidade. Esse grupo seria o principal responsável pelos números significativos em termos de vendas no mercado nacional, o que estaria gerando consequências que chegam a influenciar a circulação de obras inclusive no mercado global. Esse estudo também indica a legislação fiscal e a burocracia alfandegária como os principais entraves ao desenvolvimento internacional do mercado brasileiro, dificultando a venda e a aquisição de obras internacionais pelo mercado doméstico.

Na verdade o que o TEFAF Art Market Report de 2013 tornou mundialmente conhecido foram os resultados da pesquisa organizada pelo projeto Latitude e conduzida pela pesquisadora brasileira Ana Letícia Fialho ao longo dos últimos três anos. Segue abaixo uma breve explicação dos seus pontos mais relevantes.

\section{Projeto Latitude: uma questão cultural, comercial ou diplomática?}

Batizado de projeto Latitude - Plataforma de Galerias de Arte Brasileira ${ }^{4}$ no Exterior, o programa para a promoção internacional do setor de arte contemporânea brasileira foi criado em 2007 pela Agência Brasileira de Promoção de Exportações e Investimentos (Apex-Brasil) em parceria com a Fundação Bienal de São Paulo e de um grupo de galerias de arte brasileiras do mercado primário ${ }^{5}$. Atualmente, a plataforma conta com a participação de 52 galerias, localizadas em sete estados brasileiros $^{6}$, que no conjunto representam mais de 1.000 artistas.

Cabe aqui ressaltar que a Apex-Brasil é um órgão governamental vinculado ao Ministério das Relações Exteriores que tem por principais objetivos promover produtos e serviços brasileiros no exterior e atrair investimentos estrangeiros para setores estratégicos da economia brasileira. A intenção por trás 
desse esclarecimento é fazer notar que o projeto Latitude não está sob a ingerência do Ministério da Cultura, órgão tradicionalmente responsável pela promoção da cultura nacional, mas sim do ministério responsável por trocas institucionais, comerciais e diplomáticas entre países. Tal constatação - relacionada à forma como o governo vem lidando com as feiras de arte - leva a pensar o lugar que a arte contemporânea brasileira vem ocupando dentro das políticas públicas desenvolvidas pelo governo federal e quais seus reflexos para o meio artístico.

Antes de qualquer coisa, faz-se fundamental compreender a atuação da Apex como uma plataforma de negócios que visa disseminar a produção brasileira no exterior através de
(...) missões comerciais, rodadas de negócios, apoio à partici- pação de empresas brasileiras em grandes feiras internacionais, organização de visitas técnicas de compradores estrangeiros e de formadores de opinião com o objetivo de apresentá-los para a estrutura produtiva brasileira e outras iniciativas seleciona- das destinadas a reforçar a marca do Brasil (APEX, 2013).

Isso significa que a agência não está unicamente focada nas Artes, mas sim em toda possibilidade comercial que, a partir de estudos de mercado, se demonstre estratégica para o desenvolvimento da competitividade das empresas brasileiras e do próprio país. Com isso, chegamos à conclusão de que a arte brasileira - em especial a arte contemporânea brasileira -, para além de seu valor estético, foi detectada como um bom negócio a ser explorado comercialmente.

Desde 2011 a Apex vem destinando recursos e know-how ao projeto Latitude, que, por sua vez, é administrado e operacionalizado pela Associação Brasileira de Arte Contemporânea (ABACT). Assim, funcionando sob o formato de uma parceria público-privada (PPP), o Latitude se habilita para tratar arte e cultura como uma questão de mercado, e não de patrimônio.

Bruno Frey (2000), economista suíço, se propõe a estudar uma questão que costuma inspirar curiosidade e certa polêmica. $\mathrm{O}$ autor se questiona qual seria a melhor maneira de as autoridades públicas investirem em arte e a promoverem. Mesmo que desde um ponto de vista bastante voltado a uma compreensão do mundo a partir de cânones e conceitos da Ciência Econômica, Frey diferencia os possíveis tipos de investimento que os governos podem realizar, desde que possuindo também distintos objetivos. Ele afirma que deve haver ajuda estatal para artes em geral, porque seus mercados seriam ca- 
racterizados por aquilo que a teoria econômica clássica chamaria de "falhas" de mercado, ou seja, os custos de produção seriam superiores à sua capacidade de gerar dividendos. Isto é, devido à dimensão de bem público do produto artístico, o preço de mercado não compensaria os empreendedores privados da arte por toda a utilidade ou o benefício que dão à sociedade como um todo.

Tal pensamento de Frey está baseado em cinco esferas de valor, que seriam: 1) valor optativo: segundo o qual os indivíduos podem se beneficiar da oferta cultural mesmo que no momento não o façam; 2) valor existencial: baseado na unicidade e raridade dos bens artísticos; 3) valor de legado: referente à conservação da arte para a posteridade; 4) valor de prestígio: por conservar e promover o sentimento de identidade regional ou nacional; 5) valor relacionado ao desenvolvimento do pensamento criador e à consequente melhoria da capacidade de valoração crítica e de criação de normas estéticas em dada sociedade (2000, p. 126-7).

Ainda segundo o autor, todas essas vantagens difusas somente podem ser internalizadas em parte pelo mercado. Caberia ao Estado zelar pelos efeitos externos ou sociais positivos que os agentes do mercado não costumam levar em conta. No caso do projeto Latitude, parece que os valores de prestígio (4) e aquele relacionado ao pensamento criador (5) acabariam funcionando como argumentos de afirmação de uma identidade nacional positiva para exportação.

Gabriel Luiz Machado (2012) realizou profunda pesquisa sobre as estratégias de difusão cultural brasileira como instrumento de política externa durante os governos do presidente Lula (2002-2010). Ele se utiliza do termo "soft power", criado por Joseph Nye, que define a capacidade de um país influenciar relações internacionais, exercer um papel de encantamento e sedução através de qualidades softs, em especial manifestações culturais fortes e diversas para definir a atuação da política externa brasileira do período analisado. Para demonstrar como este conceito tem sido utilizado de maneira estratégica pelo governo federal, segue trecho de artigo publicado pela atual ministra da Cultura, Marta Suplicy, no jornal Folha de São Paulo em 24 de fevereiro de 2013:

Nós somos um país emergente, o único sem poderio bélico, mas que está descobrindo outra forma de inserção. Essa é, acredito, a grande oportunidade de consolidação e ampliação de nossa força como potência atraente para comércio, investimentos e 
turismo. Temos, portanto, o desafio de somar e coordenar esforços numa articulação estruturada que tenha a capacidade de envolver agentes públicos e privados (SUPLICY, 2013).

Segundo o discurso oficial da plataforma, o Latitude se propõe a apoiar galerias brasileiras em seus diferentes níveis de internacionalização através da profissionalização de galerias iniciantes que pretendem se dirigir a mercados consolidados e da ajuda a galerias mais experientes para manter e ampliar seus negócios. Ainda pensando em termos de "soft power", suas ações atuais têm levado em conta a recepção positiva que o país tem experimentando atualmente no cenário internacional.

Tal recepção positiva tem acontecido muito em função de o Brasil estar registrando, desde a crise de 2008 e ao contrário de muitos países europeus, índices de crescimento econômico e aquecimento dos mercados interno e externo. No final de 2011, foram registrados números que nos elevaram à 6 a economia mundial, superando temporariamente a economia do Reino Unido, e nos colocaram como um dos principais focos dos investidores internacionais. Este rearranjo nas posições de grandes economias mundiais trouxe ao Brasil como consequência certa euforia econômica que se viu refletida também no mercado da arte. Outro fenômeno nacional, consequência do crescimento econômico do País, e que foi constatado no estudo de Claire McAndrew (2013), é o rápido aumento do volume de colecionadores nacionais com alto poder aquisitivo e disposição para investir na arte brasileira (e a influenciar na sua cotação nacional e internacional).

A partir de tudo isso, cabe a pergunta indicada no subtítulo desta passagem. Quais seriam as intenções reais do projeto Latitude? Seriam elas culturais, comerciais ou diplomáticas? Como responder tais questionamentos é uma atividade que resulta bastante complexa e aparentemente circular, aproveito a menção aos colecionadores e proponho mudar a pergunta: a quem cada tipo de intenção interessa? Talvez aqui encontremos outras chaves de acesso para essas mesmas questões.

\section{Quando o público e o privado se misturam}

Voltando à fala de Marta Suplicy, ao apontar a necessidade de uma articulação entre agentes públicos e privados, a ministra reafirma uma orientação presente não apenas no Ministério da Cultura, mas uma estratégia mais ampla do Governo Federal em realizar parcerias público-privadas em diferentes instâncias. $\mathrm{O}$ amplo uso 
das leis de incentivo fiscais por parte do Ministério da Cultura é um nítido exemplo de política pública que acaba por delegar a decisão final sobre quais projetos serão efetivamente financiados nas mãos de diretores de marketing de grandes empresas.

Tal funcionamento acarreta alguns desvios na operacionalização da lei de incentivo, como, por exemplo, a consequente preferência por investimentos em projetos de caráter mais midiático, que proporcionem maior visibilidade à marca das empresas patrocinadoras sem necessariamente serem os projetos de maior mérito cultural, ou então gera concentração geográfica na viabilização de projetos localizados na região sudeste, nos estados mais populosos, onde, via de regra, essas mesmas empresas estão sediadas. Quando isso ocorre, o princípio de bem público, acessível ao grande público, fica prejudicado.

A partir desse tipo de raciocínio, Frey (200o) chama a atenção para o fato recorrente de pessoas do meio das artes pedirem ajuda "estratégica" aos governos aproveitando oportunidades para converter, ou capitalizar, os efeitos externos positivos dos bens de caráter artístico em proveito próprio. Apesar de ele afirmar que tal tipo de comportamento aconteceria nos mais diferentes países ${ }^{7}$, sabemos que o Brasil tem um histórico de apropriação do patrimônio público - em especial o cultural - pelas elites, que o utilizam não apenas para ganhos financeiros indiretos através da renúncia fiscal, mas principalmente na promoção de seus valores.

Com isso estou indicando uma tendência da contemporaneidade já apontada pela curadora e crítica de arte sueca Maria Lind (2012) em relação ao desenvolvimento e financiamento das artes hoje. Para Lind, a arte passa por um forte momento de instrumentalização, seja para servir como ferramenta de inclusão social através de atividades socioeducativas (chamadas de "responsabilidade social" pelas empresas); seja como forma de inserção no mercado de trabalho; ou mesmo para construir ou reforçar identidades nacionais em épocas de globalização e desterritorialização. A partir dessa compreensão, a autora salienta como as parcerias entre instituições públicas e ações privadas têm configurado o que conhecemos por arte nos dias de hoje. Segundo ela

Although it initially addressed the physically and administratively uniform institutions of art, this critique now embraces more or less a whole system - the "institution contemporary art", so to speak. This includes both the art market and the public apparatus, with its policies and channels for financing. 
Characteristic of this wave of institutional critique is also that those doing the criticizing implicate themselves in what is being criticized: there is no real "outside", no absolute detachment $^{8}$ (LIND, 2012).

Com isso, Lind chama a atenção para a impossibilidade de separarmos, na atualidade, a esfera econômica de qualquer outra área da vida cotidiana. Ao aceitar que "não existe fora", ou ao afirmar que preceitos de economia fazem parte da "arte contemporânea enquanto instituição", ela abre caminho para a legitimação de iniciativas como o projeto Latitude, que não se configura como uma política pública de apoio direto à produção artística, mas sim como um conjunto de estratégias e ações para incentivar o desenvolvimento do mercado de arte.

O projeto Latitude, portanto, nasceu de um encontro explícito entre as esferas pública e privada. Seu público-alvo não é o público em geral, mas sim as 52 galerias participantes da plataforma, seus cerca de 1.000 artistas representados e os compradores que passarão a adquirir a produção artística brasileira, de outra forma inacessível. Isso se dá pelo fato de que o Latitude é, antes de tudo, uma plataforma comercial desenvolvida para auxiliar empresários brasileiros (no caso, os galeristas) a exportar seus produtos. Sua operacionalização não se dá somente através de recebimento de recursos financeiros por parte do governo, mas sim principalmente pela busca de estabelecimento de medidas facilitadoras de mercado, na regulamentação de processos e na desburocratização. Ou seja, seu fim é melhorar as condições de criação e criar condições de venda para os artistas, facilitando o acesso à arte para os consumidores. Nas palavras de Frey

El aumento del apoyo estatal al arte y la cultura no tiene por qué identificarse con la concesión de fondos públicos adicionales. El examen y la flexibilización de las regulaciones administrativas y la eliminación de las restricciones burocráticas puede incentivar una ayuda más efectiva al arte y a la cultura ${ }^{9}$ (2000, p. 139).

Em termos de uma parceria efetiva entre as duas instituições, a ABACT e Apex-Brasil trabalham a partir de um calendário de atividades e investimentos definidos a cada dois anos. Este programa é construído a partir de planejamento estratégico desenvolvido para o setor, uma investigação objetiva que aponta os mercados alvo, os aspectos a serem melhorados 
e as oportunidades para a expansão sustentável do mercado de arte brasileira no exterior. Tudo a partir de um linguajar e de uma lógica de mundo empresariais (tais como a busca pela maximização do investimento realizado).

Outra atividade estratégica desenvolvida pela equipe do Latitude é o estudo setorial, que resulta na combinação de atividades, pesquisas sobre o mercado alvo e uma análise dos resultados do programa. Toda esta informação serve como um instrumento para as atividades desempenhadas pelo Latitude. Tais atividades abrangem um espectro bastante amplo, dentre elas: 1) apoio à participação das galerias em feiras de arte; 2) visita a mercados específicos para a coleta de dados e orientação de galerias brasileiras que pretendem atuar nesse mercado;3) trazer convidados estrangeiros para o Brasil para imersão em cena de arte do País, com o objetivo de criar oportunidades de negócios futuros, projetos e colaborações; 4) atividades voltadas para a disseminação de informações sobre o cenário da arte brasileira; 5) uso de ferramentas on-line para anunciar as atividades do Latitude e das galerias participantes; 6) operações de formação voltadas a preparar galerias para atividades específicas e/ou uma presença mais ampla no mercado internacional; e 7) construção contínua de um banco de dados e documentos para orientar o comitê gestor na sua tomada de decisões estratégicas.

Sobre esse conjunto de ações, Alessandra D’Aloia, atual vice-presidente da $\mathrm{ABACT}$, diz:

Essa atividade é fundamental para que tenhamos sucesso em colocar a produção brasileira no mapa internacional. Nós temos a grande oportunidade de estabelecer novas relações e trocas entre curadores, galerias e artistas. Muitas exposições, relatórios ou estudos são realizados aqui, porque nós trouxemos as pessoas certas para os eventos mais importantes no setor de arte (LATITUDE, 2013).

Ou seja, em função da característica dos produtos artísticos, essas transações comerciais trazem um adicional à equação, algo que bens de consumo comuns não trariam. $\mathrm{O}$ fato de esses produtos serem bens artísticos apenas aumenta sua capacidade de "soft power" frente ao mercado externo, configurando também uma questão de ordem diplomática e de reforço de uma identidade nacional relacionada ao poder criador e à inovação. E isso não pode ser desconsiderado, em especial em um momento no qual o Brasil busca se firmar como uma potência econômica em nível mundial. 
No entanto, cabe ressaltar que no meio artístico há quem questione a contribuição do Governo Federal e o investimento financeiro realizado em prol de um grupo específico de galerias (as associadas da ABACT) e os artistas por elas representados. Sendo um programa que tem dentre seus principais objetivos o aumento da comercialização de obras, ou seja, lucro privado, também beneficia indiretamente as coleções privadas que detenham obras de artistas por elas representados. Como mencionado acima, visitas de curadores e colecionadores internacionais a museus e instituições nacionais organizadas pelo projeto Latitude vem acontecendo periodicamente a cada feira ou evento de grande porte, como as bienais. A repercussão de tais ações é bastante difícil de mensurar, uma vez que algum resultado concreto daí advindo pode demorar anos a se materializar. Mas as escolhas das instituições e dos eventos visitados certamente influenciam no conhecimento que esses profissionais e colecionadores estrangeiros passam a ter do Brasil e da produção artística nacional, bem como configuram redes de contatos específicas.

\section{Novas latitudes para a arte brasileira}

EUA, Colômbia, Reino Unido, Alemanha, Suíça, Espanha, França, Bélgica e Hong Kong são os mercados alvo já definidos para as próximas atividades desenvolvidas pelo Latitude. Tal lista foi elaborada a partir de um parecer qualitativo realizado pelas galerias e de um estudo quantitativo organizado pela Apex-Brasil. Ele nos aponta algumas questões, como a busca por inserção e visibilidade em mercados consagrados, como EUA, Reino Unido e Suíça; mas também a expansão para latitudes a princípio menos óbvias, como é o caso da Colômbia e de Hong Kong.

Essa lista é, portanto, um reflexo da crescente polifonia do mundo da arte - transformado em mundos da arte por Hans Belting (2013). Mesmo ainda compreendendo o lugar privilegiado dos países considerados centrais como formuladores de sentidos simbólicos globais e a assimetria nos fluxos de informação como índices da configuração de poder, podemos perceber na última década uma certa atrofia da utilização do termo multiculturalismo para a proposição de um "novo internacionalismo". Isso significaria o reconhecimento do caráter multicultural do mundo por quem o observa a partir do "centro", com a invocação de gradativa aceitação de visões concorrentes sobre o que resultaria no funcionamento de um espaço global de trocas simbólicas e da progressiva mudança de lugar de enunciação dos discursos críticos e curatoriais sobre 
o que antes estava à margem do sistema de artes internacional. Tais constatações repercutem no mercado da arte e nas suas formas peculiares de construção de valor.

Nesse sentido, alguns resultados já atingidos pelo projeto Latitude demonstram seu alcance em nível internacional e levantam algumas questões sobre mudanças nos processos de valoração e legitimação na arte contemporânea, bem como das novas geopolíticas do poder econômico. O exemplo mais emblemático talvez seja o volume de exportações de galeriasmembros do Latitude ter crescido significativamente desde a sua implementação em 2007. No primeiro ano de existência do projeto, o volume de exportação foi de U\$S 6.034.872,00. Em 2012, esse número subiu para U\$S 27.130.165,00, ou seja, um crescimento de $350 \%$ em cinco anos.

Retomando o relatório da TEFAF Maastricht, podemos dizer que o Brasil vive um momento de grande visibilidade global e isso se reflete no mercado de arte. Há um grande interesse no mercado interno por parte de galerias internacionais. Ao mesmo tempo, há muita receptividade por parte de instituições estrangeiras e coleções para a produção do Brasil. Perante este cenário dinâmico e desafiador, o projeto Latitude tem se proposto a intensificar seu programa de formação e profissionalização de galerias de pequeno e médio portes e a consolidar a presença de grandes galerias em mercados globais importantes. Com atuações focadas em feiras internacionais e todo o universo de instituições, colecionadores e curadores que gravita ao redor desses eventos, o projeto Latitude tem apresentado resultados significativos, tanto de ordem comercial quanto de divulgação dos artistas e galerias nacionais.

No entanto, e apesar dos crescentes resultados obtidos até o momento, os próprios estudos setoriais do Latitude tem apontado para uma série de obstáculos ao desenvolvimento do setor de acordo com os galeristas. Tais entraves podem ser observados segundo duas categorias principais: aquela que depende da ação do governo como facilitar/incentivador dos processos envolvidos na exportação de obras de arte, como a alta carga tributária, a burocracia de exportação e a instabilidade econômica e aquela inerente à expansão do negócio em si, como dificuldades de gestão e planejamento, falta de mão de obra qualificada, bem como dificuldade de acesso a colecionadores institucionais e privados internacionais.

Outro aspecto extremamente importante a ser considerado é que, em função da falta generalizada de informações a respeito do mercado de arte brasileiro, se torna praticamente impossível 
questionar tais resultados. Por ser uma pesquisa encomendada a partir de interesses específicos - do público e do privado -, não se tem acesso aos dados brutos nem aos detalhes metodológicos, somente aos dados divulgados, que já passaram por análise e interpretação. Para muitos, fica a dúvida se resultados que sinalizariam tendências negativas frente ao mercado seriam divulgados com o mesmo entusiasmo que aqueles que registram seu intenso crescimento, indo de encontro aos interesses tanto da ABACT quanto do governo. Esses interesses parecem repousar, em grande medida, 1) para as galerias: no crescimento do mercado de arte brasileira nacional e internacionalmente como um índice de reconhecimento dessa produção, bem como uma validação da arte como um "bom negócio" e 2) para o governo: na divulgação do Brasil como um país economicamente estável e que oferece uma alta taxa de retorno sobre os investimentos feitos em arte, bem como publicitar a ideia de uma país criativo, detentor de uma produção artística competitiva, de nível internacional, que gere uma atuação positiva para a balança comercial nacional.

É possivel que em cinco anos tenhamos muito mais argumentos e capacidade de avaliar o que está acontecendo neste exato momento em termos de internacionalização da arte brasileira contemporânea. No entanto, podemos afirmar que, quaisquer que sejam os desdobramentos desse processo, o projeto Latitude disporá dos dados e informações relevantes a seu respeito, bem como será uma dos princpais responsáveis pelos rumos tomados.

\section{NOTAS}

1. "O Mercado de Arte Global, com foco na China e no Brasil".

2. No vocabulário da administração e economia, player é uma palavra usada para caracterizar os diferentes atores que efetivamente atuam em determinado cenário, contribuindo para sua configuração e resultados (THOMPSON, 2012).

3. Todas as informações a respeito do Latitude estão disponíveis no seu website: www.latitudebrasil.org

4. Lista das galerias participantes do projeto Latitude: Galeria Murilo Castro - Belo Horizonte/MG, Vermelho - São Paulo/SP, Amparo Sessenta - Recife/ PE, Galeria Millan - São Paulo/SP, Galeria Marcelo Guarnieri - Ribeirão Preto/SP, Galeria Eduardo Fernandes - São Paulo/SP, Galeria Nara Roessler - São Paulo/SP, Galeria Logo - São Paulo/SP, Galeria Berenice Arvani - São Paulo/SP, Blau Projects - São Paulo/SP, Galeria Contempo - São Paulo/SP, Galeria Lume - São Paulo/SP, Matias Brotas Arte Contemporâneo - Vitória/ ES, Galeria Luisa Strina - São Paulo/SP, Portas Vilaseca - Rio de Janeiro/RJ, Mendes Wood - São Paulo/SP, Choque Cultural - Rio de Janeiro/RJ, A Gentil Carioca - Rio de Janeiro/RJ, Galeria Rabieh, São Paulo/SP, Celma Albuquerque Escritório de Arte - Belo Horizonte/MG, Inox Galeria - Rio de Janeiro/ RJ, Almacen Galeria - Rio de Janeiro/RJ, Galeria Roberto Alban - Salvador/ BA, Luciana Brito Galeria - São Paulo/SP, Sérgio Gonçalves - São Paulo/ 
SP, Galeria Estação - São Paulo/SP, Baró - São Paulo/SP, Galeria Leme - São Paulo/SP, Mercedes Viegas Arte Contemporânea - Rio de Janeiro/RJ, Athena Contemporânea - Rio de Janeiro/RJ, Emma Thomas - São Paulo/SP, 1500 Gallery - Rio de Janeiro/RJ, Fass - São Paulo/SP, Galeria da Gávea - Rio de Janeiro/RJ, Anita Schwartz Galeria de Arte - Rio de Janeiro/RJ, Galeria Pilar São Paulo/SP, Galeria Movimento - Rio de Janeiro/RJ, Luciana Caravello Arte Contemporânea - Rio de Janeiro/RJ, Galeria Mezanino - São Paulo/SP, Casa Triângulo - São Paulo/SP, Galeria Paralelo - São Paulo/SP, Galeria Central São Paulo/SP, Bolsa de Arte - Porto Alegre/RS, Galeria Raquel Arnaud - São Paulo/SP, Sim Galeria - Curitiba/PR, Silvia Cintra + Box 4 - Rio de Janeiro/RJ, Ybakatu Espaço de Arte - Curitiba/PR, Galeria Laura Marsiaj - Rio de Janeiro/ RJ, Galeria Marília Razuk- São Paulo/SP, Galeria Fortes Vilaça - São Paulo/SP, Galeria Jaqueline Martins - São Paulo/SP, Zipper Galeria - São Paulo/SP.

5. Mercado primário é aquele que intermedeia a venda da obra direto do ateliê do artista para o comprador. Mercado secundário é quando a obra entra no mercado para revenda (de um colecionador a outro). Neste caso, a intermediação geralmente é feita por casa de leilões ou por galerias especializadas neste segmento (THOMPSON, 2012).

6. As galerias são de São Paulo (SP), Rio de Janeiro (RJ), Curitiba (PR), Porto Alegre (RS), Belo Horizonte (MG), Vitória (ES) e Salvador (BA). Do total, apenas seis não estão localizadas no eixo Rio-São Paulo, sendo duas de Curitiba, uma de Porto Alegre e uma de Belo Horizonte, Vitória e Salvador.

7. Frey (2000) menciona tal situação sem citar casos específicos, dando a entender que seria uma situação generalizada. Wu (2006) fez uma extensa comparação entre as formas de lidar com o patrimônio cultural e a atuação das esferas pública e privada nos EUA e no Reino Unido, mostrando como fatores culturais mais profundos influenciam diretamente na relação das formas de financiamento das artes em ambos os países.

8. "Apesar de inicialmente ter abordado as instituições de arte física e administrativamente, essa crítica agora abraça mais ou menos todo um sistema - a 'arte contemporânea' enquanto instituição, por assim dizer. Isso inclui tanto o mercado de arte quanto o aparelho público, com as suas políticas e os canais de financiamento. Característica desta onda de crítica institucional é também que aqueles que fazem a crítica estão implicados no que está sendo criticado: não existe 'fora', nem desprendimento absoluto" (LIND, 2006, tradução da autora).

9. "O aumento do apoio estatal à arte e à cultura não precisa estar vinculado à concessão de fundos públicos adicionais. O exame da flexibilização das regulações administrativas e a eliminação de restrições burocráticas podem incentivar a arte e cultura de uma forma mais efetiva" (FREY, 2000, p. 139, tradução da autora).

\section{Referências}

BELTING, Hans; BUDDENSIEG, Andrea; WEIBEL, Peter (eds.). The Global Contemporary and the Rise of New Art Worlds, ZKM | Center for Art and Media Kalrsruhe, Germany and The MIT Press: Cambridge, MA/London, England, 2013.

FREY, Bruno. La Economía del Arte. Collección Estudios Económicos. Número 18. La Caixa: Barcelona, 2000.

LIND, Maria; VELTHIUS, Olav (orgs.). Contemporary Art and Its Commercial Markets: A Report on Current Conditions and Future Scenarios. Sternberg Press, Tensta Konsthall, 2012, p. 270. MACHADO, Gabriel Luiz. A difusão cultural brasileira como 
instrumento de política externa: estratégias contemporâneas. Universidade Federal do Rio Grande do Sul. Faculdade de Ciências Econômicas. Curso de Relações Internacionais, Porto Alegre, BR-RS, 2012, p. 73.

McANDREW, Clare. TEFAF Art Market Report 2013. The Global Art Market, with a focus on China and Brasil. The European Fine Art Foundation. Disponível em <www.tefaf.com $>$. Acesso em 18 de novembro de 2013.

SUPLICY, Marta. O "soft power" brasileiro. In: Folha de São Paulo, 24 de fevereiro de 2013. Disponível em <http://www1. folha.uol.com.br/fsp/opiniao/95343-o-quotsoft-powerquot -brasileiro.shtml>. Acesso em 18 de novembro de 2013.

THOMPSON, Don. O tubarão de 12 milhões de dólares: a curiosa economia da arte contemporânea/Don Thompson; tradução Denise Bottmann. BEI Comunicação, 2012.

WU, Chin-Tao. Privatização da cultura: a intervenção corporativa nas artes desde os anos 8o. São Paulo: Boitempo, 2006.

Site oficial da ABACT, disponível em <http://abact.com.br/>. Acesso em 16 de novembro de 2013.

Site oficial da Apex-Brasil, disponível em <http://www2.apexbrasil.com.br/>. Acesso em 16 de novembro de 2013.

Site oficial do projeto Latitude, disponível em <http://www. latitudebrasil.org>. Acesso em 15 de novembro de 2013.

Recebido em: 16/10/14

Aceito em: 15/11/14

\footnotetext{
BRUNA WULFF FETTER

brunafetter@gmail.com

Doutoranda em História, Teoria e Crítica pelo PPGAV/UFRGS. Recentemente dividiu a curadoria da mostra Mutatis Mutandis com Bernardo de Souza, no Largo das Artes (2013); assinou a curadoria da exposição Lugar Qualquer, do artista Rommulo Vieira Conceição na Casa Triângulo (2013); e compartilhou com Angélica de Moraes a curadoria de mostra desse mesmo artista, no Centro Cultural da Funarte em São Paulo. Traz em sua bagagem profissional a produção de projetos de artes visuais, como Agora/Ágora, Horizonte Expandido e a coordenação da equipe de produção da 6a Bienal do Mercosul.
} 